Rev Biomed 2004; 15:173-180.

\title{
Lupus eritematoso: enfermedad autoinmune sistémica y órgano específica.
}

\section{Revisión}

Sergio H. Sánchez-Rodríguez ${ }^{1}$, Gerardo E. Barajas-Vásquez ${ }^{1}$, Elena D. Ramírez-Alvarado ${ }^{1}$, Alejandra Moreno-García ${ }^{1}$, Olga Y. Barbosa-Cisneros².

${ }^{1}$ Departamento de Inmunología y Biología Molecular, Centro de Biología Experimental, Universidad Autónoma de Zacatecas. ${ }^{2}$ Laboratorio de Biología Celular. Facultad de Ciencias Químicas. Universidad Autónoma de Zacatecas. Zacatecas, México.

\section{RESUMEN.}

En los pacientes que desarrollan lupus, su sistema inmune se activa y se vuelve contra el mismo huésped, por lo que es considerada una enfermedad autoinmune. En los Estados Unidos, existe más de un millón de personas que presenta Lupus. Sus síntomas aparecen en una gran variedad de formas, en los cuales la mitad de los casos es letal. El daño aparece en cualquier órgano del cuerpo y puede causar artritis con inflamación, fatiga, eritema en alas de mariposa en región malar, úlceras orales, fotosensibilidad, serositis (inflamación del tejido alrededor del corazón y pulmón), osteoporosis, desórdenes renales (proteinuria y destrucción celular), desórdenes sanguíneos (leucopenia, linfopenia, trombocitopenia, anemia hemolítica), desórdenes inmunológicos (anticuerpos anti-DNA y anti-Sm) y títulos de anticuerpos antinucleares anormales.

Utilizando técnicas de biología molecular, se han descubierto algunos factores que regulan el sistema inmune, así como mecanismos bioquímicos por los cuales en el lupus se presenta daño al tejido. También se han identificado algunos genes candidato que parecen estar involucrados en el lupus.

(Rev Biomed 2004; 15:173-180)

Palabras Clave: Lupus eritematoso, anticuerpos, autoinmunidad, antígenos, autoanticuerpos.

\section{SUMMARY.}

Lupus erythematosus: systemic autoimmune and organ specific disease.

The immune system of patients with Lupus becomes activated and reacts against themselves, which is why it is considered an autoimmune disease. In the USA more than one million people have Lupus. The symptoms appear in a variety of forms, and half of the cases are lethal. The damage may appears in any organ of the body and can cause arthritis with

Solicitud de sobretiros: Dr. Sergio H. Sánchez-Rodríguez. Departamento de Inmunología y Biología Molecular. Centro de Biología Experimental. Universidad Autónoma de Zacatecas. Calzada de la Revolución s/n, Col. Tierra y Libertad. C.P. 98600. Apartado postal 12. Guadalupe, Zacatecas, México. Tel/Fax (492) 921-13-26. Correo electrónico: smdck@hotmail.com Recibido el 14/Noviembre/2003. Aceptado para publicación el 20/Febrero/2004. 


\section{SH Sánchez-Rodríguez, GE Barajas-Vásquez, ED Ramírez-Alvarado, A Moreno-García y col.}

inflammation, fatigue, facial o malar rash, oral ulcers, photosensitivity, serositis (inflammation of tissue around the lung and heart), renal disorders (proteinuria, cellular destruction), blood disorders (leukopenia, lymphopenia, thrombocytopenia, hemolytic anemia), immunological disorders (anti-DNA, anti-Sm antibodies), and abnormal antinuclear antibody titles.

Using molecular biology techniques some factors that regulate the immune system and biochemistry mechanisms of tissues damage in lupus have been discovered. In addition some genes that appear to be involved in the generation of lupus have been identified. (Rev Biomed 2004; 15:173-180)

Key Words: Lupus erythematosus, antibodies, autoimmunity, antigens, autoantibodies.

\section{INTRODUCCIÓN.}

El nombre de lupus es de origen incierto, proviene del latín Lupus que significa lobo, ya que las lesiones en el rostro de la gente afectada por el Lupus recuerda una mordedura de lobo. Fue hasta 1981 que se le dio el nombre de Lupus Eritematoso Sistémico (LES), que hoy en día, se considera una enfermedad compleja y misteriosa, más que su propio nombre. En los Estados Unidos más de un millón de personas afectadas con Lupus, presentan una gran variedad de síntomas. En más de la mitad de los casos es letal. Estudios realizados en Nueva York, demuestran que el $90 \%$ de los pacientes con Lupus son mujeres, en donde las afroamericanas son tres veces más susceptibles a desarrollar la enfermedad que las de raza blanca (1).

El Lupus se presenta en edades que van de 15 a 40 años durante los picos de fertilidad, por lo que los estrógenos, hormonas sexuales femeninas, se consideran como un factor clave en el desarrollo del Lupus. Los factores ambientales pueden disparar el Lupus. Por ejemplo, la luz solar, que exacerba la enfermedad induciendo entre otros factores, la inflamación y alteraciones a nivel renal en algunos pacientes. La prescripción de ciertas drogas, en donde se incluyen medicamentos para el corazón y antipsicóticas, pueden causar efectos lupídicos. Los virus y bacterias pueden afectar al sistema inmunológico haciéndolo más susceptible a su desregulación (1).

Los pacientes con Lupus desarrollan entre otros, anticuerpos anti-Sm, los cuales son dirigidos contra el DNA de todas las células, aunque pacientes sanos también tienen este tipo de anticuerpo, con la diferencia de que está dirigido al DNA bacterial, en donde se postula la hipótesis de que, probablemente, en la producción de estos anticuerpos anti-DNAbacterial se dé un cambio y reconozcan el DNA del huésped. Se han encontrado secuencias de aminoácidos del Virus Epstein-Barr (EBV), agente causal de la mononucleosis, que están relacionadas con un anticuerpo anti-Sm en el 30\% de pacientes con Lupus (1).

Estudios realizados en ratón, han mostrado que los anticuerpos anti-DNA se unen específicamente a la proteína alfa-actinina en la superficie de las células de riñón indicando, de alguna manera, porqué en el Lupus se afecta al riñón $(1,2)$. Estos anticuerpos antiDNA también se asocian a un péptido del receptor celular neural conocido como NMDA (N-metil-Daspartato) involucrado en el desarrollo de la memoria, lo cual explica el porqué estos pacientes con lupus tienen una pérdida gradual de la agudeza y memoria mental (1).

Se conoce que el nucleosoma es fundamental en el empaquetamiento del genoma eucariótico, y es el substrato de una gran cantidad de procesos en el núcleo (3). En el lupus eritematoso sistémico (LES) humano, la doble hebra de ADN es el mayor autoantígeno. Los autoanticuerpos en pacientes con LES son del isotipo IgG. Además, es conocido que son marcadores de células $\mathrm{T}$ cooperadoras. $\mathrm{La}$ respuesta de células $T$ a autoantígenos, incluyendo el ADN desnudo y ADN compuesto o empaquetado (nucleosoma), ha sido reportada únicamente en pacientes con LES (4). Se ha observado que el nucleosoma media la unión de autoanticuerpos en la membrana basal glomerular en la nefritis lúpica humana y se sugiere que este mecanismo puede ocurrir en otros sitios del cuerpo (5). Se ha encontrado que anticuerpos antinucleosoma del isotipo $\mathrm{IgG} 3$, ayudan en el

\section{Revista Biomédica}




\section{Lupus eritematoso sistémico.}

diagnóstico diferencial en enfermedades del tejido conectivo, como un marcador especifico para LES, en particular, en nefritis lúpica (6). El LES correlaciona con la presencia de niveles altos de anticuerpos antihistona $\mathrm{H} 1$ (7).

Se cree que algunos genes pueden estar involucrados en el desarrollo del Lupus, los cuales se localizan en los cromosomas 1, 4 y 6 . Hay tres candidatos fuertes: el primero, que corresponde al gen de la molécula del Complejo Mayor de Histocompatibilidad Clase II (MHC-II); el segundo, que codifica para proteínas del complemento y, un tercero, que afecta receptores IIa y IIIa de inmunoglobulinas. Sin embargo, al menos una docena de genes están siendo investigados; no es clara su participación, aunque algunos están involucrados en la actividad de células T y B y otros, en la tolerancia (1).

\section{LUPUS ERITEMATOSO.}

El Lupus Eritematoso (LE), es una enfermedad autoinmune del tejido conjuntivo que se caracteriza por afección de la piel, articulaciones, riñón, sistema nervioso central, vasos, y huesos, entre otros; estos pacientes desarrollan síntomas generales como fatiga y alteraciones inmunológicas características, además de autoanticuerpos circulantes con diferente especificidad, y la actividad inflamatoria es secundaria a la formación de complejos inmunes circulantes. La enfermedad se clasifica en una forma puramente cutánea, el lupus eritematoso discoide (LED), lupus neonatal (LN), lupus eritematoso cutáneo subagudo (SCLE) y una forma generalizada, el lupus eritematoso sistémico (1).

\section{LUPUS ERITEMATOSO SISTÉMICO.}

El LES es una enfermedad autoinmune que se caracteriza por la presencia de autoanticuerpos y un infiltrado linfocitario en las lesiones de piel, riñón y otros órganos. Y en sangre periférica se han detectado linfocitos que median la producción de autoanticuerpos. Ambos podrían ser considerados factores patogénicos en la generación de las lesiones $(8,9)$. El padecimiento afecta prácticamente a todos los aparatos y sistemas; sin embargo, las manifestaciones cutáneas son las más comunes (90\%) y la afección renal le confiere un pronóstico especial. El depósito de complejos inmunes DNA/anti-DNA en el endotelio glomerular parece jugar un papel de gran importancia en la inducción de glomerulonefritis, donde también se ha destacado la participación del complemento, citocinas y substancias proinflamatorias en el daño a los glomérulos (10).

En relación a los factores ambientales, se ha demostrado que la exposición a la luz solar desencadena o agrava las lesiones cutáneas en el LES, ya que éstas se presentan habitualmente en zonas expuestas al sol. La fracción ultravioleta de 290-320 nm (UV-B) induce daño al DNA de las células epidérmicas, con la probable expresión de antígenos ocultos, que en presencia de autoanticuerpos inducen la formación de complejos inmunes in situ. Algunos de éstos quedan atrapados en la unión dermoepidérmica, observándose por inmunofluorescencia la banda lúpica característica (figura 1A)(11), donde también pueden detectarse cuerpos citoides en dermis papilar, de IgG, IgM, C3 y fibrinógeno en biopsias de piel $(9,12,13)$.

De tal forma que la participación cutánea en el lupus es muy frecuente y las lesiones pueden ser agudas o crónicas. La lesión aguda más representativa es el eritema en alas de mariposa que corresponde a lesiones en región malar y dorso de la nariz (figura 1B)(14), además de otras áreas expuestas al sol, como el cuello y los brazos (12). Las lesiones crónicas, son llamadas discoides y en la mayoría de los casos, representan la forma cutánea del padecimiento. Los principales síntomas de LES se enuncian en la cuadro $1(1,15)$.

\section{LUPUS ERITEMATOSO DISCOIDE (LED).}

El LED se presenta en todas las razas. A diferencia del LES, es más común en mujeres mayores de 40 años de edad y tiene una evolución crónica e insidiosa. El LED constituye una lesión crónica, consistente en placas eritematosas con descamación, que se localizan en piel cabelluda, orejas, cara y cuello. Los pacientes con LES y lesiones discoides 
SH Sánchez-Rodríguez, GE Barajas-Vásquez, ED Ramírez-Alvarado, A Moreno-García y col.

Tabla 1

Los principales síntomas que se presentan en pacientes con LES (1).

\begin{tabular}{lc}
\hline Síntomas & Frecuencia \% \\
\hline Exantema facial (alas de mariposa) & $42 \%$ \\
o malar & \\
Pérdida de cabello & $27 \%$ \\
Fotosensibilidad & $30 \%$ \\
Úlceras orales & $12 \%$ \\
Artritis con inflamación & $90 \%$ \\
Serositis (inflamación de tejido alrededor & $45 \%$ \\
de pulmones y corazón & \\
Desorden renal & $50 \%$ \\
Desórdenes sanguíneos: leucopenia, & $20 \%$ \\
linfopenia, trombocitopenia & \\
Desórdenes neurológicos: psicosis, & \\
Desórdenes inmunológicos: anticuerpos & \\
anti-DNA y anti-Sm & \\
Títulos anormales de anticuerpos antinucleares \\
Anemia & $71 \%$ \\
Astenia y adinamia & $81 \%$ \\
Fiebre 38 ${ }^{\circ}$ C o más. & $90 \%$ \\
Dolor articular (artralgia) & $95 \%$ \\
Rash en piel & $74 \%$ \\
Fenómeno de Raynaud's & $17 \%$ \\
\hline
\end{tabular}

habitualmente tienen baja incidencia de complicaciones renales (figura $1 \mathrm{C})(16,17,18)$.

Los exámenes de laboratorio generalmente son negativos. Sin embargo, algunas formas diseminadas pueden cursar con anemia hemolítica y/o trombocitopenia discretas, aun cuando también se pueden presentar leucopenia y/o linfopenia, hipergammaglobulinemia, y crioglobulinas y anticuerpos anti-nucleares a títulos bajos. Los depósitos inmunes a nivel de unión dermo-epidérmica ("banda lúpica"), solamente se observan en biopsias de piel enferma (18).

Dado que la exposición a la fracción ultravioleta (UV) de la luz solar incrementa las lesiones, es indispensable usar filtros o protectores solares y evitar los medicamentos y/o substancias fotosensibilizantes (18).

\section{LUPUS NEONATAL (LN).}

El síndrome de LN es una enfermedad rara debida al paso transplacentario de anticuerpos antinucleares con especificidad Ro y/o La, de una madre con lupus al producto; de tal forma que el infante neonatal presenta lesiones cutáneas transitorias de lupus eritematoso cutáneo subagudo (SCLE) y en ocasiones también presenta bloqueo cardíaco

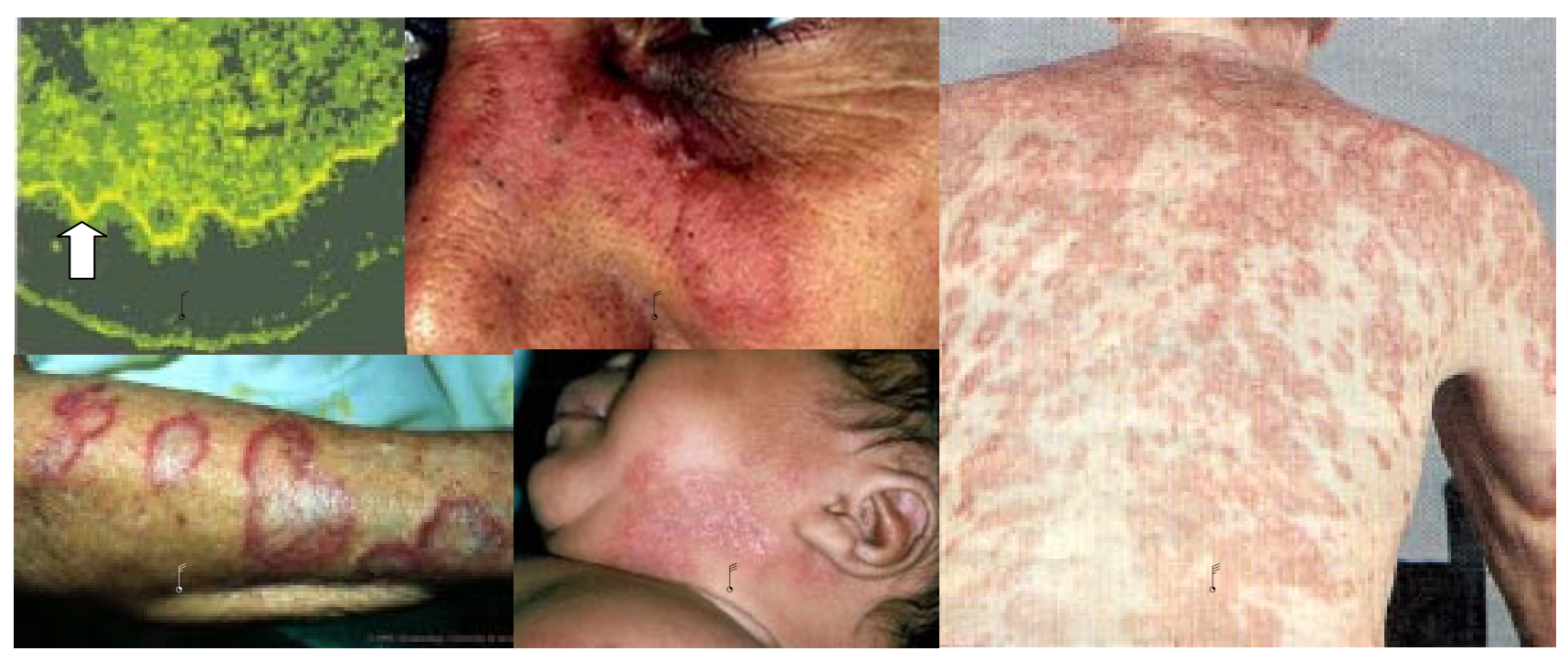

Figura 1.- Banda lúpica, observada en biopsia de piel por inmunofluorescencia indirecta utilizando un suero de paciente con LE. La flecha indica la unión dermoepidérmica en donde se depositan los complejos inmunes (A). Lesión cutánea: eritema en alas de mariposa en el rostro de un paciente con LE (B). Lesión característica de lupus discoide (C). Lupus eritematoso Neonatal (D). Lesión característica de lupus eritematoso cutáneo subagudo (E).

\section{Revista Biomédica}




\section{Lupus eritematoso sistémico.}

congénito (BCC). La incidencia de esta patología es de 1 en 20,000 recién nacidos vivos. La mitad de los casos de LN exhibe lesiones cutáneas (figura 1D) $(19,20)$, la otra mitad presenta BCC y sólo en un $10 \%$ se presentan ambas. En relación al BCC, se presenta durante la vida intrauterina y puede ser detectado desde la $16^{\mathrm{a}}$ y $24^{\mathrm{a}}$ semana, pero con frecuencia es irreversible (20).

Histológicamente se presenta una fibrosis del sistema de conducción y en ocasiones el nodo aurículo-ventricular se calcifica. La fibrosis ocasiona un bloqueo que por lo general es permanente, la mitad de los recién nacidos con BCC se compensa y no requiere de tratamiento, la otra mitad necesita un implante de un marcapaso. Aún con este recurso, el $10 \%$ de los recién nacidos afectados no responde al tratamiento y muere de insuficiencia cardíaca (20).

\section{LUPUS ERITEMATOSO CUTÁNEO SUBAGUDO (SCLE).}

Recientemente algunas formas de lupus denominadas seronegativas, han despertado gran interés clínico por su asociación con los anticuerpos anti-Ro. Tal es el caso de una variante fotosensible que fue descrita por Sontheimer y Gilliam. Las lesiones clínicas están constituidas por lesiones policíclicas, eritematoescamosas no cicatriciales con características e histología similar a la del LES. La distribución de éstas ocurre principalmente en áreas expuestas al sol, especialmente en la parte superior del tórax, dorso de brazos, antebrazos, cuello y, en ocasiones, existen lesiones en la cara, piel cabelluda y extremidades inferiores (figura 1E)(21,22).

La característica serológica del SCLE es la presencia de anticuerpos anti-Ro en un 60\% y en un $36 \%$ anti-La. Algunos pacientes pueden desarrollar en forma concomitante síntomas de Sicca (disminución de las secreciones) hasta en un 44\%. Sin embargo, el dato clínico más relevante es la fotosensibilidad, cuyas lesiones inclusive pueden ser inducidas por exposición a la radiación ultravioleta (12).

\section{EFECTO DE LA LUZ SOLAR EN PIEL.}

La piel que es expuesta a la luz solar permite que la fracción UV-B penetre la epidermis y sea absorbida en la parte superior de la dermis, en tanto que la irradiación UV-A penetra hasta lo más profundo de la dermis. A las moléculas responsables de absorber la luz se les denomina cromóforos. La melanina es el principal cromóforo, el cual absorbe longitudes de onda que van desde 350 a $1200 \mathrm{~nm}$. La luz absorbida puede producir cambios químicos en un proceso que se llama fotoquímica y al rango de longitud de onda con suficiente energía para causar estos cambios se le denomina espectro de absorción (22).

Los efectos inducidos por exposición a longitudes de onda específicas de irradiación UV-A y UV-B a nivel de la piel, se han estudiado en distintos modelos experimentales de inflamación, provocando diferentes lesiones tisulares. Por ejemplo, la exposición aguda resulta en eritema, calor, edema, dolor y prurito, seguida por un bronceado y engrosamiento epidérmico (22); en tanto que la exposición crónica puede inducir envejecimiento cutáneo y cáncer en áreas expuestas al sol, como cuello, cara y áreas dorsales de los brazos $(23,24)$.

El daño tisular post-irradiación es mediado por citocinas inflamatorias que son producidas por los linfocitos, y en forma no profesional, por células de la piel como los queratinocitos y fibroblastos. Durante el proceso inflamatorio inducido por radiación ultravioleta (R-UV) se ha observado un aumento drástico en la producción y secreción de los niveles de Interleucina-1 (IL-1) $(22,24,25)$, Interleucina-1alfa (IL-1-a), Interleucina-1-beta (IL1-b) (26), Interleucina-6 (IL-6), Interleucina-8 (IL-8) y el factor de necrosis tumoral alfa (TNF-a) (22-25,27). Así mismo, se ha observado que los queratinocitos irradiados expresan el receptor de factor de necrosis tumoral de $55 \mathrm{kDa}$ (TNF-RI). Este receptor induce directa o indirectamente la proliferación celular, además de la expresión de moléculas de adhesión intracelular (ICAM-I) (28).

\section{FOTORREACTIVIDAD Y LUPUS.}

La relación de las lesiones cutáneas de lupus y la exposición a la luz solar se conocía desde principios de siglo XX, pero no fue hasta 1965, con los trabajos 
SH Sánchez-Rodríguez, GE Barajas-Vásquez, ED Ramírez-Alvarado, A Moreno-García y col.

de John Epstein, que se demostró que las lesiones eran inducidas por la fracción de R-UV (29). Con la descripción de las variedades fotosensibles de lupus y su asociación con anticuerpos anti-Ro60, la causa de la fotosensibilidad se ha explorado experimentalmente. Así, Le Feber y col. detectaron en queratinocitos in vitro un aumento en la expresión de las ribonucleoproteínas nucleares y citoplásmicas, después de ser irradiados con la fracción B de la RUV. Por otra parte, los estudios de Norris y col. indican que el antígeno Ro60 se transloca a la membrana plasmática de los queratinocitos como efecto de la irradiación UV-B (13). Sin embargo, los datos experimentales de Cassiola-Rosen (30) y de Ávalos-Díaz (31), muestran un incremento en la expresión de la proteína Ro60, así como cambios apoptóticos en queratinocitos en cultivo irradiados con luz UV-B. Otros estudios muestran que la redistribución del antígeno Ro60 es inducido de manera paralela a la activación de los genes apoptóticos fas-L y bax, como causa de la irradiación con luz UV-A (32).

\section{DAÑO BIOLÓGICO PROVOCADO POR LA LUZ ULTRAVIOLETA (L-UV).}

En la piel, la L-UV tiene una considerable actividad biológica, causando daño a las estructuras moleculares de los ácidos nucleicos, lípidos, algunos aminoácidos y componentes de la membrana celular $(23,33)$. No obstante, el rango de los efectos varía de acuerdo a la intensidad y a la longitud de onda administrada, de tal forma que altas dosis de radiación UV-A producen eritema que puede estar relacionado con la citotoxicidad de los queratinocitos (22). Por otra parte, la R-UV-B por más de 24 horas provoca que los queratinocitos sean incapaces de reparar el DNA dañado, como resultado del rompimiento lisosomal.

La respuesta de los ácidos nucleicos al estímulo de la irradiación UV-B y UV-C, es la formación de dímeros de pirimidinas adyacentes. Estos dímeros son cuantificados en las células por el número de sitios sensitivos a las endonucleasas (ESS) $(34,35)$. Asimismo, la R-UV provoca un incremento del calcio intracelular, que es otra vía de activación de las endonucleasas endógenas, y da como resultado la fragmentación del DNA (36). No obstante, existe una respuesta contraria, la fotorreactivación (FRA), que es un proceso natural detectado en células procariontes y eucariontes, que consiste en la acción de la enzima fotorreactivadora fotoliasa, que cataliza la monomerización de los dímeros de pirimidinas, en un proceso de reparación del DNA. Esta enzima se activa con la absorción de luz visible o dosis específicas de L-UV $(35,37)$.

Otra respuesta de las células de la piel al tratamiento con L-UV de longitud de onda corta (UVC) o drogas que dañan el DNA, es el incremento en la síntesis o represión de algunas proteínas a través de la formación de un heterodímero, el factor de transcripción AP-1, por activación de los genes c-fos y c-jun (25). Asimismo, las tres longitudes de onda de L-UV inducen la producción de la proteína supresora de tumores p53, que tiene la función de monitorear la integridad y estabilidad de la célula (23). Otros factores involucrados en la respuesta tardía, son el factor nuclear kappa B (NFkB), factores de crecimiento y la secreción de algunas proteasas $(22,38)$.

\section{CONCLUSIONES.}

El lupus eritematoso es una enfermedad autoinmune del tejido conjuntivo. El daño aparece en cualquier órgano del cuerpo y puede causar una gran variedad de síntomas. Los estrógenos, hormonas sexuales femeninas, se consideran un factor en el desarrollo del lupus. Asímismo, factores ambientales pueden disparar el Lupus; por ejemplo, la luz solar que exacerba la enfermedad. Los virus y bacterias pueden afectar al sistema inmunológico haciéndolo más susceptible a su desregulación provocando el fenómeno de autoinmunidad.

La complejidad de la enfermedad impide una investigación clínica precisa, ya que un síntoma puede ser curado, otro puede ser minimizado, pero se pueden desarrollar otros síntomas peores debido al tratamiento previo, ya que las terapias que se ofrecen para controlar la enfermedad incluyen corticoesteroides y

\section{Revista Biomédica}




\section{Lupus eritematoso sistémico.}

compuestos citotóxicos de alto riesgo.

\section{REFERENCIAS.}

1.- Marshall Eliot. Lupus: Mysterious disease holds Its secrets tight. Science 2002; 296:689.

2.- Mason LJ, Evans JG, Putterman C, Isenberg DA. AntidsDNA antibodies purified from patients with lupus nephritis bind to alpha-actinin. http://www.abstractonline.com/viewer/ searchAdvancedResults.asp

3.- Flaus A, Tom Owen-Hughes T. Mechanisms for nucleosome movilization. Biopolymers. 2003; 68:563-78.

4.- Bruns A, Bläss S, Hausdorf G, Burmester GR, Hiepe F. Nucleosomes are major $\mathrm{T}$ and $\mathrm{B}$ cell autoantigens in systemic lupus erythematosus. Arthritis \& Rheumatism. 2000; 43:230715.

5.- Grootscholten C, van Bruggen MCJ, van der Pijl JW, de Jong EMGJ, Ligtenberg G, Derksen RHWM, et al. Deposition of nucleosomal antigens (histones and DNA) in the epidermal basement membrane in human lupus nephritis. Arthritis \& Rheumatism. 2003; 48:1355-62.

6.- Amoura Z, Koutouzov S, Chabre H, Cacoub P, Amoura I, Musset L, et al. Presence of antinucleosome autoantibodies in a restricted set of connective tissue diseases: Antinucleosome antibodies of the IgG3 subclass are makers of renal pathogenicity in systemic lupus erythematosus. Arthritis \& Rheumatism. 2000; 43:76-84.

7.- Schett G, Rubin RL, Steiner G, Hiesberger H, Muller S, Smolen J. The lupus erythematosus cell phenomenon: Comparative analysis of antichromatin antibody specificity in lupus erythematosus cell-positive and -negative sera. Arthritis \& Rheumatism. 2000; 43:420-8.

8.- Kita Y, Kuroda K, Mimori T, Hashimoto T, Yamamoto K, Saito Y, et al. T cell receptor clonotypes in skin lesions from patients with systemic lupus eryhematosus. J Invest Dermatol 1998; 110:41-6.

9.- Chan LS, Vanderlugt CJ, Hashimoto T, Nishikawa T, Zone JJ, Black MM, et al. Epitope spreading: lessons from autoimmune skin diseases. J Invest Dermatol 1998; 110:1039.

10.- Villalobos-Hurtado R, Avalos-Díaz E, Herrera-Esparza R. Inmunorreactantes glomerulares en nefropatía lúpica. Boletín CIAR 1996; 6:3-6.
11.- Bollain-y Goytia JJ. (Tesis). La luz ultravioleta A aumenta la transcripción de los genes fas-L y bax y contribuye a la redistribución de la proteína Ro60 de queratinocitos. Unidad Académica de Biología Experimental: Universidad Autónoma de Zacatecas; 2001.

12.- Provost TT, Watson R. Anti-Ro(SS-A) HLA-DR3positive women: the interrelationship between some ANA negative, SS,SCLE, and NLE mothers and SS/LE overlap female patients. J Invest Dermatol 1993; 100:14-20.

13.- Norris DA. Pathomechanisms of photosensitive lupus erythematosus. J Invest Dermatol 1993; 100:58-68.

14.- Discoid lupus erythematosus. www.dermnetnz.org/ dna.discoid/info.html

15.- LUPUS. If you (or one of your loved ones) have Lupus, you will remember this day for the rest of your life. Why? www.thehomeostasisprotocol.com

16.- Discoid lupus erythematosus. www.skinsite.com/ info discoid lupus erythematosus.htm

17.- Discoid lupus erythematosus. tray.dermatology.uiowa.edu/DLE-003.htm

18.- Werth VP, Duts JP, Sontheimer RD. Pathogenetic mechanism and treatment of cutaneous lupus erythematosus. Curr Op Rheumatology 1997; 9:400-9.

19.- Callen JP. Neonatal lupus and cutaneous lupus erythematosus in children. Copyright 2003, eMedicine.com, Inc.

20.- Buyon JP. Autoantibodies reactive with Ro(SS-A) and La (SS-B) and pregnacy. J Rheumatol 1997; 24:12-16.

21.- Lupus cutané subaigu. Article publié dans la revue Actualité Médicale. Du 29 janvier 1997; 18(4). www.callisto.si.usherb.ca/ 94268233/medecine.htm

22.- Hruza LL, Pentland AP. Mechanisms of UV-induced inflammation. J Invest Dermatol 1993; 100:35-41.

23.- Berton TR, Mitchell DL, Fischer SM, Locniskar MF. Epidermal proliferation but not the quantity of DNA photodamage is correlated with UV-induced mouse skin carcinogenesis. J Invest Dermatolol 1997; 109:340-7.

24.- Avalos-Díaz E, Alvarado-Flores E, Herrera-Esparza R. UVA irradiation stimulates the synthesis of inflammatory cytokines in human dermal fibroblasts. Rev Rhum 1999,66:13-9.

Vol.15/No.3/Julio-Septiembre, 2004 


\section{SH Sánchez-Rodríguez, GE Barajas-Vásquez, ED Ramírez-Alvarado, A Moreno-García y col.}

25.- Rosette C, Karin M. Ultraviolet light and osmotic stress: activation of the JNK cascade through multiple growth factor and cytokine receptors. Science 1996; 274:1194-7.

26.- Konodo S, Sauder DN, Kono T, Galley KM, McKenzie RC. Differential modulation of interleukin-1a (IL-1a) and interleukin-1b (IL-1b) in human epidermal keratinocytes by UVB. Exp Dermatol 1994; 3:29-39.

27.- Kemény L, Michel G, Ruzicka T. Cytokine system as potential target for antipsoriatic therapy. Exp Dermatol 1994; $3: 1-8$.

28.- Trefzer U, Brockhaus M, Lötscher H, Parlow F, Budnik A, Grewe M, et al. The 55-KD tumor necrosis receptors on human keratinocytes is regulated by tumor necrosis factoralpha and by ultraviolet B radiation. J Clin Invest 1993; 92:46270.

29.- Kind P, Lehmann P, Plewig G. Phototesting in lupus erythematosus. J Invest Dermatol 1993; 100:53-7.

30.- Cassiola-Rosen LA, Anhalt GJ, Rosen A. Autoantigen targeted in systemic lupus eryhematosus are clustered in two populations of surface blebs on cultured keratinocytes. J Exp Med 1994; 179:1317-30.

31.- Avalos-Díaz E, Aguilera-Galaviz A, Herrera-Esparza R. UV-A Irradiation increases the expression of the $60 \mathrm{kD}$ Ro antigen in human keratinocytes. Chron Derm 1996; 6:791801.

32.- Bollain-y-Goytia JJ, Avalos-Díaz E, Herrera-Esparza R. Fas ligand and Bax gene trascription contributes to Ro60 ribonucleoprotein redistribution in UV-A irradiated human keratinocytes. Joint Bone Spine. 2000; 67:283-9.

33.- Zheng ZS, Chen RZ, Prystowsky JH. UVB radiation induces hosphorylation of the epidermal growth factor receptor, decreases EGF binding, and blocks EGF induction of ornithine decarboxylase gene expression in SV40transformed human keratinocytes. Exp Dermatol 1993; 2:25765.

34.- Wantanabe R, Otsuka F. Cultured skin fibroblasts derived from three patients disseminated superficial actinic porokeratosis (DSAP) are hypersensitive to the lethal effects of X-radiation but not to those of ultraviolet (UV) light. Exp Dermatol 1993; 2:175-8.

35.- Tanew A, Ortel B, Hönigsmann H. UVA does not photoreactivate pyrimidine dimers in cultured human fibroblasts. Exp Dermatol 1993; 2:161-4.

\section{Revista Biomédica}

36.- Benassi L, Ottani D, Fantini F, Marconi A, Chiodino C, Giannetti A, et al. 1,25-Dihydroxyvitamin D3, transforming growth factor B1, calcium, ultraviolet B irradiaton induce apoptosis in cultured human keratinocytes. J Invest Dermatol 1997; 109:276-82.

37.- Herrlich P, Rahmsdorf HJ. Transcriptional and posttranscriptional responses to DNA-damaging agents. Curr Op Cell Biol 1994; 6:425-31.

38.- Pahl HL, Baeuerle PA. Control of gene expression by proteolysis. Curr Op Cell Biol 1996; 8:340-7. 